\title{
SYNCHRONOUS ESOPHAGEAL SQUAMOUS CELL CARCINOMA AND GASTRIC ADENOCARCINOMA
}

\author{
Carcinoma epidermóide de esôfago e adenocarcinoma gástrico sincrônicos \\ Janina Ferreira Loureiro HUGUENIN, Vitor Vargas Zampieri de AZEVEDO, \\ Herbert Ives Barreto ALMEIDA, Ivanir Martins de OLIVEIRA, Carlos Eduardo PINTO
}

From the Section of the Abdominal-Pelvic Surgery, National Cancer Institute - INCA, Rio de Janeiro, RJ, Brazil.

\section{Correspondence:}

Janina Ferreira Loureiro

E-mail: janinaloureiro@hotmail.com

Financial source: none

Conflicts of interest: none

Received for publication: 01/03/2012

Accepted for publication: 31/01/2013

\section{INTRODUCTION}

S quamous cell carcinoma of the esophagus is occasionally associated with other malignancies, particularly of the respiratory tract and the head and neck ${ }^{1,2,3}$. Presentation of synchronous gastric adenocarcinoma is rare but important to be investigated, due the stomach is the main organ used for reconstruction of the alimentary tract after esofagectomies ${ }^{4}$. In cases where there are synchronous gastric tumors, the colon becomes option for transit reconstruction .

Although this association between gastric and esophageal tumors is not representative in Western countries, the incidence is increasing in Eastern countries $^{5}$. In Brazil, few cases are described, with no estimation in our country.

\section{CASE REPORT}

Male 71 years old, white, smoker, married and complaining six months of heartburn, early satiety, melena and weight loss. Evolved with dysphagia for solids in the past two months. At physical examination, performance status of 1 , with no palpable lymphadenopathy. Pulmonary and cardiac auscultation were normal. Abdomen was without palpable masses, nor rectal examination.

Endoscopy showed ulcerated lesion affecting $70 \%$ of the circumference of the mid-lower thoracic esophagus and another ulcerative-infiltrative lesion in the gastric antrum, circumferential to the pylorus, without stenosis, more than $10 \mathrm{~cm}$ of the esophagogastric junction. The biopsy diagnosed esophageal squamous carcinoma and gastric adenocarcinoma.

CT of chest, abdomen and pelvis dismissed pleural effusion or chest lymphnodes. Showed concentric thickening of the lower third of the esophagus, in gastroesophageal junction, antrum and lymph node along the lesser gastric curvature . Liver was normal in size and contour, without signs of focal lesions .

The patient underwent transhiatal esophagogastrectomy full lymphadenectomy and reconstruction with left colon and jejunostomy. Histopathology confirmed the presence of esophageal squamous cell carcinoma around $7.5 \times 6.5 \mathrm{~cm}$ to 4.5 $\mathrm{cm}$ proximal margin of gastric adenocarcinoma and Borrmman III $4.0 \times 2.5 \mathrm{~cm}$ to $2.0 \mathrm{~cm}$ distal margin (Figure 1). Were isolated to total 60 lymph nodes, two of which were positive for squamous cell carcinoma (one in right cardic group and one in left) and two were positive for adenocarcinoma in the small curvature. The pathological classification for esophageal tumor was pT3pN1 and the gastric tumor pT4apN1a .

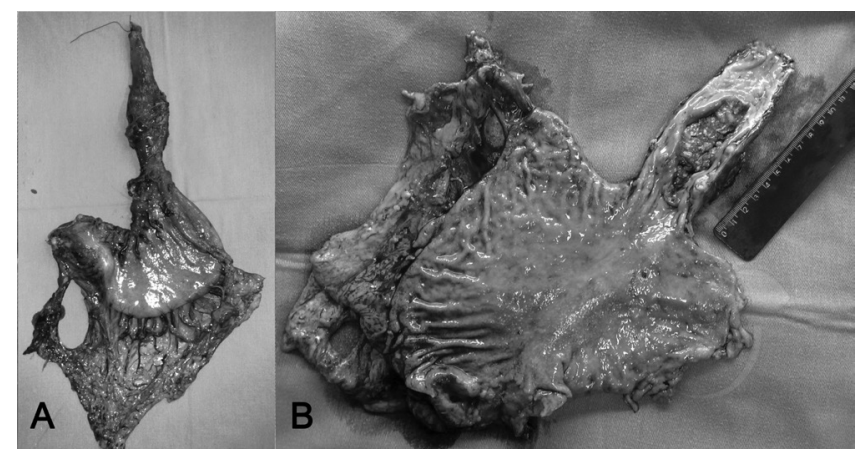

FIGURE 1 - A) Surgical specimen: segment of the esophagus, stomach and duodenum; B) open surgical specimen showing tumor with $4.5 \mathrm{~cm}$ from proximal margin in esophagus and in antrum Borrmman III with distal margin of $2.0 \mathrm{~cm}$ and 60 isolates lymph nodes resected

The patient had an uneventful postoperative time, staying in ICU until the $2^{\text {nd }}$ day after surgery, when the diet was also introduced by jejunostomy. On the $10^{\text {th }}$ day a barium swallow did't show any leak, and 
then oral diet was started with good acceptance. He was discharged on the $20^{\text {th }}$ postoperative day.

\section{DISCUSSION}

With the increasing of survival time in cancer patients, and better screening programs for early detection of neoplastic lesions, synchronous and metachronous tumors are being related ${ }^{6,9}$. The squamous cell carcinoma of the esophagus has been described in association with gastric adenocarcinoma primarily in Japan in 1980; data from the Japanese Committee for Diseases of the Esophagus showed that of the 11,732 cases of esophageal tumors resected in Japan 186 (1.6 \%) were tumor-associated with gastric tumors ${ }^{7}$.

Hamabe et $\mathrm{al}^{8}$, in a retrospective study of 288 patients with primary tumors of the esophagus resected, obtained 17 (5.9\%) with concomitant second primary tumor. Of these, 11 (3.8\%) were adenocarcinoma, being all male. These 11 patients were treated with partial or total esophagogastrectomy and reconstruction according to the size and location of gastric injury. The remaining stomach itself was used in three patients, colon and jejunum in seven. The authors concluded that in cases of synchronous esophageal and gastric tumors appropriate surgical procedures should be chosen based on the staging, localization and surgical experience.

Koide et al ${ }^{4}$ retrospectively evaluated a series of 208 patients with esophageal tumors of which 24 $(11.5 \%)$ had synchronous tumors in the stomach. In relation to the histological type of gastric lesions, 12 (5.6\%) were adenocarcinoma, eight benign lesions, one carcinoid tumor, two intramural metastatic lesions, two metastatic lymph node and submucosal tumor of unknown origin. The treatment for esophageal lesion was esophagectomy with lymphadenectomy via thoracotomy in 18 patients, transhiatal esophagectomy in four and only palliative bypass in two cases. Regarding gastric lesions were performed 10 total gastrectomy with lymphadenectomy, two proximal gastrectomy with lymphadenectomy, four extended resections (including distal pancreatectomy and/or splenectomy associated gastrectomy), six partial gastric resection (leiomyoma) and three resections of gastric lesion (adenoma). The survival of the patients with esophageal tumor was only the same when compared with the two neoplasms synchronously. The authors highlight the importance of the diagnosis of gastric tumor synchronous tumor of the esophagus by interference in the management of these patients and also stimulate the resection of both tumors whenever feasible.
Shibuya and colaboradores ${ }^{10}$ studied patients with tumors of the head and neck and esophageal tumors. Of the 434 patients with esophageal tumors, 47 (10.8\%) had synchronous tumors and 107 (24.6\%) metachronous. Among the synchronous esophageal neoplasms, 23 cases (5.2\%) had tumors of the head and neck and 16 (3.6 \%) associated gastric lesions.

The precise incidence of a second primary tumor varies between series. This difference can be explained by the different segments and also by genetic and environmental factors.

In Brazil, few cases are described. In Rio Grande do Sul, in a series of 261 patients with esophageal squamous cell carcinoma, 19 (7.28\%) had a second malignancy associated ${ }^{11}$. In 10 of 19 cases were synchronous tumors, of which four (1.5\%) were gastric adenocarcinomas. Two of these patients had both resected, while the other two only palliative treatment (radiotherapy or esophageal prosthesis).

The existence of synchronous tumors of the esophagus and stomach is a rare event, but their identification is essential for adequate surgical planning. Whenever possible, the radical surgical treatment should be carried out treating both neoplasms.

\section{REFERENCES}

1. Goodner JT, Watson WL. Cancer of the esofhagus. Its association with other primary cancers. Cancer 1956;9:1248-52

2. Cahan WG, Castro EB, Rosen PP, Strong PP, Strog EW. Separate primary carcinoma of the esophagus and head and neck region in the same patient. Cancer 1976;37:85-89

3. Goldstein HM, Zorno ZAJ. Association of squamous cell carcinoma of the head and neck with câncer of the esophagus. Am J Roentgenel 1978;131:791-794

4. Koide N, Adachi W, Koike S. Synchronous gastric tumor associated with esophageal cancer. A retrospective study of 24 patients. Am Jour Gastr 1998;93:758-762

5. Kato $H$, Tachimori $Y$, Watanabe $H$, et all. Esophageal carcinomas simultaneously associated with gastric carcinomas: analysis of clinicopathologic features and treatment. J. Surg Oncol 1994;56:122-127

6. Bae JS, Lee JH, Bae JM. Characteristics of Synchronous cancer in gastric cancer patients. Cancer 2006;38(1):25-29

7. Abo S, Miura H, Kudo T, et al. Concurrent câncer of the esophagus and other organ in Japan [Abstract]. Jpn J Gastroenterol Surg 1980;13:377

8. Hamabe $\mathrm{Y}$, Ikuta $\mathrm{H}$, Yanamoto M. Clinicopathological features of esophageal câncer with simultaneously associated with gastric câncer. Jour Surg Oncol 1998;68:179-182

9. Suzuki S, Nishimaki T, Hatakeyama K. Outcomes of simultaneous resection of synchronous esophageal and extraesophageal carcinomas. J Am Coll Surg 2002; 195:23-28

10. Shibuya $H$, Wakita $T$, Yasunomoto $M$. The relation between an esophageal cancer and associated cancers in adjacente organs. Cancer 1995;76:101-105

11. Schirmer CC, Gurski R, Castro MA, Madruga GS, Brentano L. Neoplasias associadas ao carcinoma epidermóide do esôfago. Rev Ass Med Brasil 1997;43(4):335-9 